
\title{
Research S Surate \\ The Effects of Chronic Branched-Chain Amino Acid Supplementation on Running Kinematics: Single Case Research
}

Tara K. Whiton ( $\square$ tara.k.whiton@gmail.com )

University of Maine at Presque Isle https://orcid.org/0000-0001-9098-0548

Kimitake Sato

East Tennessee State University

Caleb Bazyler

East Tennessee State University

Brad DeWeese

East Tennessee State University

Michael H Stone

East Tennessee State University

Research article

Keywords: Running, Kinematics, chronic branched-chain amino acid (BCAA) supplementation

Posted Date: September 22nd, 2020

DOl: https://doi.org/10.21203/rs.3.rs-80714/v1

License: (a) This work is licensed under a Creative Commons Attribution 4.0 International License. Read Full License 
The Effects of Chronic Branched-Chain Amino Acid Supplementation on Running Kinematics: Single Case Research

${ }^{1}$ Tara K. Whiton, ${ }^{2}$ Kimitake Sato, ${ }^{2}$ Caleb D. Bazyler, ${ }^{2}$ Brad H. DeWeese, ${ }^{2}$ Michael H. Stone ${ }^{1}$ University of Maine at Presque Isle

${ }^{2}$ East Tennessee State University

Tara K. Whiton - 181 Main Street Presque Isle, ME 04769 - tara.whiton@ maine.edu Kimitake Sato - 1276 Gilbreath Dr, Johnson City, TN 37614 - satok1 @ mail.etsu.edu Caleb D. Bazyler - 1276 Gilbreath Dr, Johnson City, TN 37614 - bazyler@ mail.etsu.edu Brad H. DeWeese - 1276 Gilbreath Dr, Johnson City, TN 37614 - deweese@ mail.etsu.edu Michael H. Stone - 1276 Gilbreath Dr, Johnson City, TN 37614 - stonem@ mail.etsu.edu

Corresponding author: Tara K. Whiton

Key words: Branched-chain amino acids, running economy, sport nutrition, sport performance 
Abstract

Purpose: To monitor the effects of chronic branched-chain amino acid (BCAA) supplementation on running kinematics in a trained ultra-endurance runner. Methods: One well-trained ultraendurance runner followed three 10-day cycles of an AB design consuming a BCAA drink (SUP) or placebo (PLA) surrounding daily key workouts leading up to a 50-mile race (dosage $=$ $0.08 \mathrm{~g} / \mathrm{kg} / \mathrm{day}=3.52 \mathrm{~g} \mathrm{BCAA} /$ day and $10.32 \mathrm{~g} \mathrm{AA} /$ day). During each 10-day cycle, the athlete completed a $5 \mathrm{~km}$ run on an outdoor track at 6:30 min/mile pace. A 10-meter capture zone was measured and marked with two orange cones for video recording and analysis. Kinovea opensource software (Version 0.8.15) was used to measure running kinematic variables: ground contact time (GCT), flight time (FT), and vertical oscillation (VO). Results: Vertical oscillation (VO) during a constant-pace run was significantly reduced from $88 \mathrm{~mm}$ to $76 \mathrm{~mm}$ when athlete was on SUP vs PLA condition $(\mathrm{p}=0.00$, Tau-U $=0.40)$. Statistical significance was not achieved for differences in GCT and FT between SUP and PLA $(p=0.06$, Tau-U $=0 .-17$ and $p=$ 0.28 , Tau- $\mathrm{U}=0.10$ for GCT and FT, respectively). Weighted Tau-U results suggest that the BCAA supplement was overall $11 \%$ effective in improving combined measures of running kinematics ( $\mathrm{p}=0.04$, Tau-U $=0.11$ ). Discussion: A decrease in VO can indicate less overall muscle support requirements during stance phase and a reduced aerobic demand for a given task. We observed decreased VO during the $5 \mathrm{~km}$ running tests on SUP indicating a reduction in wasteful vertical motion. Possible explanations for this could relate to improvement in muscle recovery characteristics from increased availability of BCAAs resulting in less chronic fatigue. Less fatigue can allow greater coactivation between two-joint muscles of the leg during stance resulting in more efficient joint rotations that are transferred into desired external forces, promoting more efficient movement and a more economical runner. 
Introduction

Activities (such as running) that include an eccentric contraction component result in exercise-induce muscle damage with a subsequent inflammatory response (Peake, Nosaka, $\&$ Suzuki, 2005). This inflammatory response is responsible for initiating tissue repair and remodeling (Hyldahl \& Hubal, 2014; Peake et al., 2005). Specifically, satellite cells, inflammatory cells, vascular cells, and stromal cells all interact with each other within the extracellular matrix of skeletal muscle and the time course of each is dependent on the magnitude of recovery necessary from muscular damage (Hyldahl \& Hubal, 2014; Peake et al., 2005). Exercise-induced muscle damage from eccentric contraction components cause sarcomere damage as evidenced by Z-disk streaming and likely directly reduce force production characteristics (Peake et al., 2005). Sarcomere damage is not a single event, but may cause opening of stretch-activated channels, membrane disruption, and excitation-contraction coupling dysfunction resulting in a prolonged loss of muscle strength (Hyldahl \& Hubal, 2014; Peake et al., 2005).

In addition to loss of muscle strength and power, other symptoms include delayed onset muscle soreness (DOMS), swelling, reduced range of motion of the affected body part, an efflux of inflammatory enzymes, or a combination of these (Hyldahl \& Hubal, 2014). These symptoms often peak around 1-3 days after exercise (Hayashi et al., 2017) and are a normal part of an athlete's recovery adaptation process. Some research has shown a reduction in symptoms of exercise-induced muscle damage and fatigue with BCAA supplementation (Beelen et al., 2010; E. Blomstrand et al., 1996; Kim, Kim, Jeong, \& Lee, 2013b; K. Matsumoto et al., 2009b; Sharp \& Pearson, 2010). In addition, a review of the literature by (9) suggested that BCAA supplementation can be effective on reducing outcomes of exercise-induced muscle damage, as 
long as the extent of muscle damage was low-to-moderate, the supplementation strategy combined a high daily BCAA intake (>200 mg/kg/day) greater than 10 days, and was especially effective if taken prior to the damaging exercise.

Protein and BCAA supplementation practices surrounding training sessions has a culture that is deep-rooted in the strength training community with a wealth of research that supports the harmonious relationship between increased protein availability and enhanced postexercise muscle protein synthesis (MPS) for muscle remodeling and repair (10). In contrast, the use of dietary protein supplements in the endurance training community is relatively recent (11). Endurance athletes who undertake prolonged (i.e. $>1 \mathrm{~h}$ ) training bouts or who train multiple times a day (but not always in a glycogen-depleted state) subject their muscles to prolonged periods of net catabolism that may impact enhancement of MPS and whole body muscle protein balance in the postexercise recovery period (11). Further, the mechanical events associated with continuous endurance training undoubtedly result in skeletal muscle structural and protein damage that requires nutritional intervention (12-14).

While the repair and remodeling of damaged muscle proteins is still a primary goal for endurance athletes who consume protein/BCAA supplements, benefits also include synthesizing new proteins that directly influence aerobic training adaptations (including myofibrillar, mitochondrial, and associated enzyme complexes) (11). This repair, remodeling, and synthesis of proteins underpins many of the training-induced adaptations that athletes seek and are ultimately related directly to the quality of muscle (i.e. mitochondrial density and/or cross-sectional area) responsible for improved sport performance (i.e. improved running economy) $(11,15)$. Many endurance events provide athletes with a carbohydrate only option post-race, (e.g. bananas), however, the most important nutritional factor in enhancing postexercise MPS is the ingestion of 
dietary protein $(11,16-18)$. While carbohydrate ingestion alone can halt further protein breakdown, it has little effect on MPS and does not further the dietary amino acid induced stimulation of MPS after exercise (16, 17, and 19).

Amino acid oxidation can provide up to $10 \%$ of total energy during endurance exercise (20). This enhanced oxidation arises from the breakdown of muscle proteins into amino acids which are released from the muscle for hepatic gluconeogenesis and/or deaminated and oxidized within muscle mitochondria as a direct source of fuel (19-22). Further oxidation of endogenous amino acids supports muscle contraction and can be enhanced by several factors such as exercise intensity and/or duration and low muscle glycogen availability (19-21, 23). This in turn leads to decreased substrate availability that may limit or prolong postexercise muscle protein repair and synthesis (19).

Whole-body rates of amino acid oxidation still remain elevated above rest with an estimated $1.2 \mathrm{~g}$ of total body leucine loss over 2 hours of moderate intensity endurance exercise ( 60\% VO2max) (24). When amino acids are oxidized during exercise they are lost from the body and unable to contribute to the increased MPS observed during recovery therefore necessitating dietary replacement $(21,24)$. Several studies have shown that an increased supply of BCAAs prior to exercise may have a sparing effect on muscle glycogen degradation during exercise as well as a decreased rate of release of essential amino acids from exercising muscle and therefore a decreased rate of protein degradation $(19,22,25)$. Where fatigue symptoms from training are a major factor influencing running economy, we chose various running kinematics to observe as fatigue indices during a constant-paced $5 \mathrm{~km}$ training run between chronic conditions of SUP or a PLA (15). Theoretically, the BCAA may promote a greater MPS and recovery from day to day training resulting in a decreased fatigue state, improved running mechanics, and 
therefore a greater running economy than when on a PLA. Therefore, the purpose of this study was to investigate the influence of BCAA supplementation on various running kinematics during constant-paced $5 \mathrm{~km}$ training runs in a trained ultra-endurance runner.

\section{Methods}

Subject

One well-trained, experienced ultra-endurance runner was monitored during one macrocycle leading up to a 50-mile running competition. Inclusion criteria were determined by training status and experience level and were met by the criteria of 1.) had to be currently training for an ultra-endurance event, and 2.) had previously competed in an ultra-endurance event. This athlete was consistently a top 20 placement finisher in all lifetime races. Prior to participation, the athlete read and signed a written informed consent document that was approved by the East Tennessee State University Institutional Review Board.

\section{Laboratory testing}

Prior to beginning the study, the athlete underwent two lab testing sessions for assessment of fitness and determination of training paces to be incorporated into his training program. Each laboratory testing session included a velocity at $\mathrm{VO}_{2} \max (\mathrm{vVO} 2 \mathrm{max})$ test (26, 27). The $\mathrm{vVO}_{2}$ max testing sessions took place on a laboratory treadmill (Tuff Tread Model RL35023-N5-1K, Willis, TX) using a metabolic cart (ParvoMedics TrueOne 2400 Metabolic Measurement System, Sandy, UT) to measure gas exchange. Testing sessions were separated by one week to eliminate the influence of fatigue on performance and results were averaged. Prior to each testing session, the athlete consumed the same self-selected breakfast meal. Collected variables during the $\mathrm{vVO} 2 \max$ test were $\mathrm{VO} 2 \mathrm{max}$ and peak treadmill running velocity, as the latter has been shown to predict performance in $10 \mathrm{~km}-90 \mathrm{~km}$ running specialist (27). In addition, 
aerobic and anaerobic ventilatory thresholds (VT1 \& VT2) were obtained using the ventilatory equivalents method and visual inspection. Training paces for programming were calculated from a percentage of the athlete's $\mathrm{VO} 2 \mathrm{max}$ and corresponding treadmill running velocities to correspond with zones established by running coach Dr. Jack Daniels (E, M, T, I, \& R, or - easy, marathon, threshold, tempo, interval, and repetition, respectively).

Training

The athlete's training plan was composed of 10-day mesocycles (vs. the traditional 7-day mesocycle that is typical for runners to follow) to allow more recovery time/restoration sessions that are necessary, but often neglected, from the intense training that an ultra-endurance event requires. The running training plan followed a polarized model with Zones 1, 2, \& 3 demarcated by ventilatory thresholds $1 \& 2$. Key workouts in the running plan included: 1.) Back-to-back long runs - one shorter, followed by one longer the next day for 1 set/mesocycle. The shorter long-run was prescribed as $65 \%$ of the following day's long run through the special prep phase. The longer runs were built off the percentage of the peak long-run mileage mesocycle which included a training race of 31 miles plus the mileage of the shorter long run of 7 miles to total 38 miles for the back-to-back peak mileage long-run. Thirty-eight miles was $75 \%$ of the 50 -mile goal. The long runs started at $40 \%$ of the 31-mile single-session run which was equal to a 12.5 mile-long run in the first cycle of the training program; 2. Tempo/Threshold Runs occurred once/mesocycle and followed a progressive build up to a 40-minute steady-state; 3. Speed or Hill session - once/alternating mesocycles where speed sessions started at tempo pace (Zone 2) during general preparation and advanced to interval pace (Zone 3) during specific preparation. Hill intervals increased in distance, degree of inclination, and speed to build specific strength for being able to run over mountainous, varying terrain. 
In addition to a running training plan, the athlete followed a block-periodized strength training program that incorporated the basic principles of progressive overload and used relativeintensities for training load prescription. Strength sessions were prescribed 3 times/mesocycle (or 3 sessions every 10 days), through the special preparation period, and thereafter decreased to 2 sessions/cycle through the competition and taper phase.

Intervention

Following 4 cycles of an $\mathrm{AB}$ single-blind design, the athlete consumed either $\mathrm{BCAA}$ drink or placebo before and after every key workout every day through his goal race. The BCAA drink and placebo were isocaloric and flavor matched. Each condition lasted the duration of one mesocycle (10 days) and then was reversed. In addition, conditions were randomized so that the athlete wasn't always on SUP on his heaviest training cycle. The athlete consumed the manufacturer recommended product dosage of $0.08 \mathrm{~g} / \mathrm{kg}$ that was split evenly between a "preworkout" and "post-workout" supplement so that before the workout $0.04 \mathrm{~g} / \mathrm{kg}$ of product was consumed, and after $0.04 \mathrm{~g} / \mathrm{kg}$ of product was consumed which resulted in a total of $10.32 \mathrm{~g}$ of total amino acids/day for this athlete (see Table 4.1). Dosages were portioned out, labeled "pre" or "post" in baggies, and given to the athlete at the beginning of each mesocycle to consume before/after workouts. 
Table 4. 1. Composition and dosages of pre-and post-workout supplements.

PRE-WORKOUT (0.04g/kg)

Serving size $5.6 \mathrm{~g}=1$ stick pack

$\begin{array}{cccc}\text { Amino Acid } & \text { Serving }(\mathrm{g}) & \mathrm{g} \text { per } 1 \mathrm{~g} & \text { Athlete's Serving Size }(\mathrm{g}) \\ \text { Leucine } & 0.528 & 0.094 & 0.93 \\ \text { Isoleucine } & 0.424 & 0.075 & 0.75 \\ \text { Valine } & 0.36 & 0.064 & 0.64 \\ \text { Total BCAA } & \mathbf{1 . 3 1 2} & \mathbf{0 . 2 3 9} & \mathbf{2 . 3 2} \\ \text { Arginine } & 0.6 & 0.106 & 1.06 \\ \text { Glutamine } & 0.622 & 0.11 & 1.10\end{array}$

TOTAL AMINO ACIDS

6.81

\section{POST-WORKOUT $(0.04 \mathrm{~g} / \mathrm{kg})$}

Serving size 8.24 = 1 scoop

Amino Acid
Leucine
Isoleucine
Valine

Total BCAA

Arginine

Glutamine

Serving $(g)$
0.438
0.33
0.28
$\mathbf{1 . 0 4 7}$
0.47
0.488

$\mathrm{g}$ per $1 \mathrm{~g}$

0.053

0.04

0.034

0.127

0.057

0.059
Athlete's Serving Size (g)

0.50

0.38

0.32

1.20

0.54

0.56 


\section{Monitoring}

Once per mesocycle and condition, the athlete completed a running field test on an outdoor track. The run was $5 \mathrm{~km}$ and performed at a $6: 30 \mathrm{~min} / \mathrm{mile}$ pace that was associated with the athlete's prescribed marathon pace - the approximate effort at which an ultra endurance race would be performed. Prior to starting the run, the athlete measured a 10-meter capture zone on the same section of track and marked the zone with two orange cones. A video camera (30fps $\mathrm{x}$ 1080p) was set up on the side of the track, far enough away so that the entire capture zone and horizon were in view. After a warm-up, the athlete turned the video camera on and proceeded with the $5 \mathrm{~km}$ run using the Garmin 220 GPS wrist-watch to allow pace monitoring. Video-taped $5 \mathrm{~km}$ field tests were analyzed using Kinovea open-source software (Version 0.8.15) for running kinematic variables such a ground contact time (GCT), flight time (FT), and vertical oscillation (VO).

Statistical analysis

Tau-U single-case research technique was used to observe the effect that each condition had on running kinematics (GCT, FT, and VO). The Tau-U effect size represented a percentage of nonoverlap between phases and will be described as percent effectiveness of the BCAA condition (28).

Results

Vertical oscillation (VO) during a constant-pace run was significantly reduced by $13.0 \%$ from $88 \mathrm{~mm}$ to $76 \mathrm{~mm}$ when athlete was on SUP vs PLA condition $(\mathrm{p}=0.00$, Tau-U $=0.40)$. Statistical significance was not achieved for differences in GCT $(-2.05 \%)(0.206 \mathrm{~s}$ vs $0.211 \mathrm{~s}, \mathrm{p}=$ 0.06, Tau-U = 0.-17 for PLA and SUP, respectively) and FT $(8.05 \%)(0.037 \mathrm{~s}$ vs $0.034 \mathrm{~s}, \mathrm{p}=$ 0.28, Tau-U $=0.10$ for PLA and SUP, respectively). However, weighted Tau-U results suggest 
that the BCAA supplement was overall $11 \%$ effective in improving measures of running kinematics $(\mathrm{p}=0.04$, Tau- $U=0.11$ ) likely due to the highly favorable results from a reduction in VO where Tau-U indicated that SUP was $40 \%$ effective in reducing VO. In addition, while a reduction in flight time was not statistically significant, we did observe an $8 \%$ improvement while on SUP. See Tables 4.2 and 4.3, and Figures 4.1, 4.2, and 4.3, below.

Table 4.2. Tau-U results for SUP vs PLA on running kinematics (GCT, FT, and VO)

\begin{tabular}{c|c|c|c|c}
\hline CONDITION & TAU & SDtau & P Value & Cl 90\% \\
\hline S-GCT vs P-GCT & -0.1791 & 0.0962 & 0.063 & $-0.337<>-0.021$ \\
\hline S-FT vs P-FT & 0.1037 & 0.0962 & 0.281 & $-0.055<>0.262$ \\
\hline S-VO vs P-VO & 0.4056 & 0.0962 & 0.000 & $0.247<>0.564$ \\
\hline
\end{tabular}

Table 4.3 Means and percent change in running kinematics (GCT, FT, and VO) between SUP and PLA

\begin{tabular}{c|c|c|c}
\hline CONDITION & GCT(s) & FT(s) & VO(mm) \\
\hline SUP & 0.211 & 0.034 & 76 \\
\hline PLA & 0.206 & 0.037 & 88 \\
\hline \% Difference & $-2.05 \%$ & $8.05 \%$ & $13.14 \%$ \\
\hline
\end{tabular}




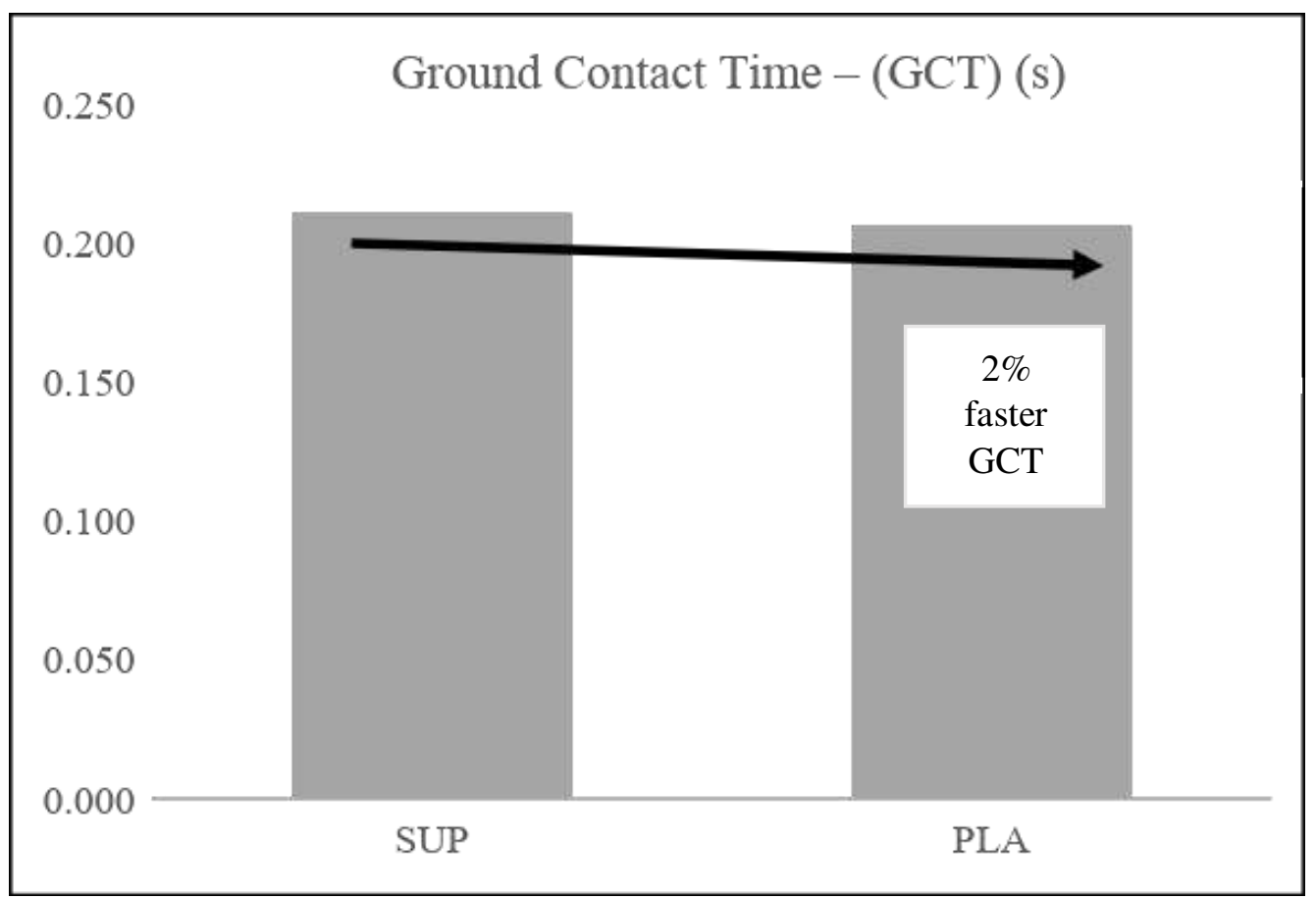

Figure 4.2. Flight time on SUP vs PLA conditions

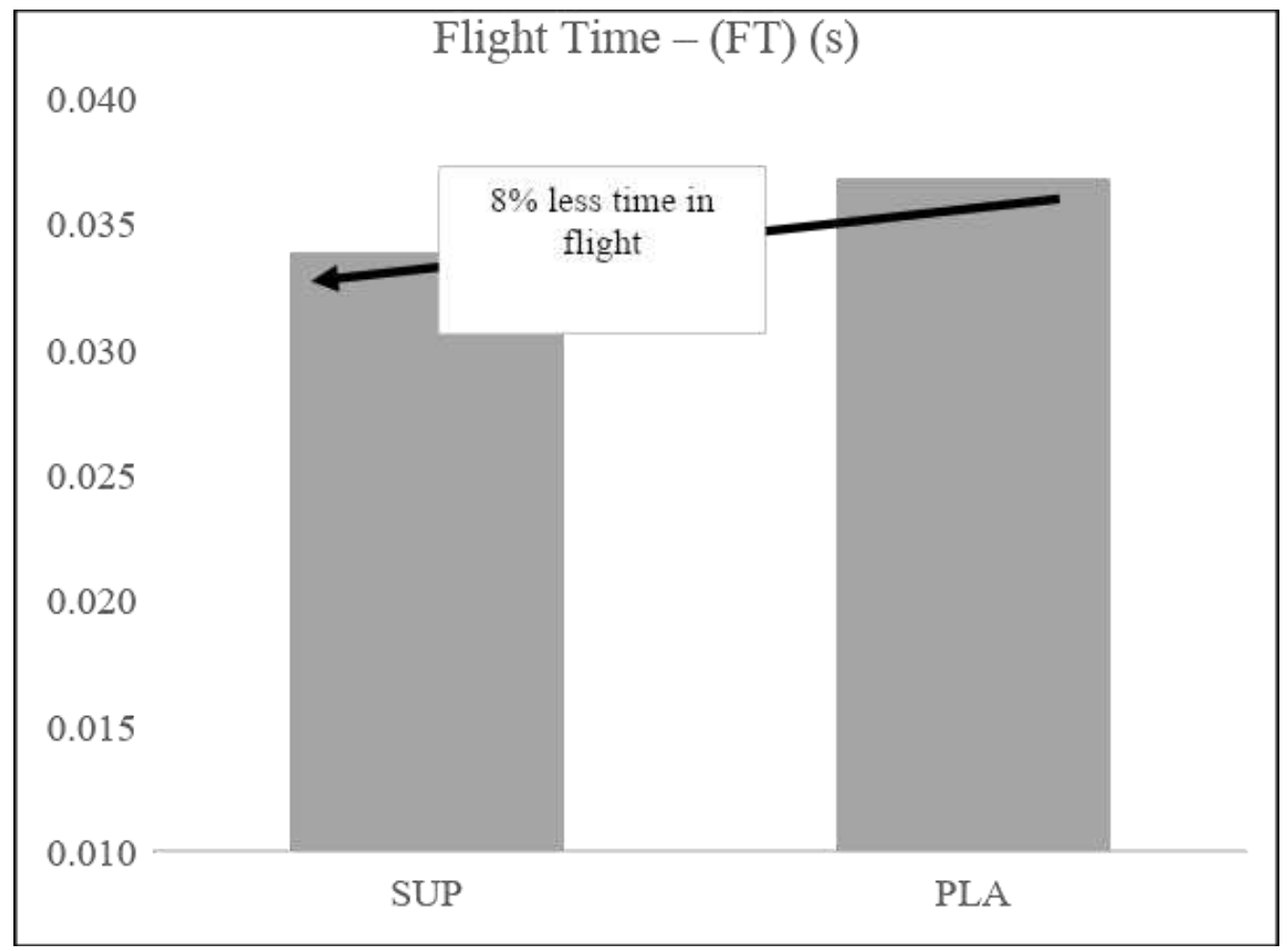


Figure 4.3 Vertical oscillation on SUP vs PLA conditions

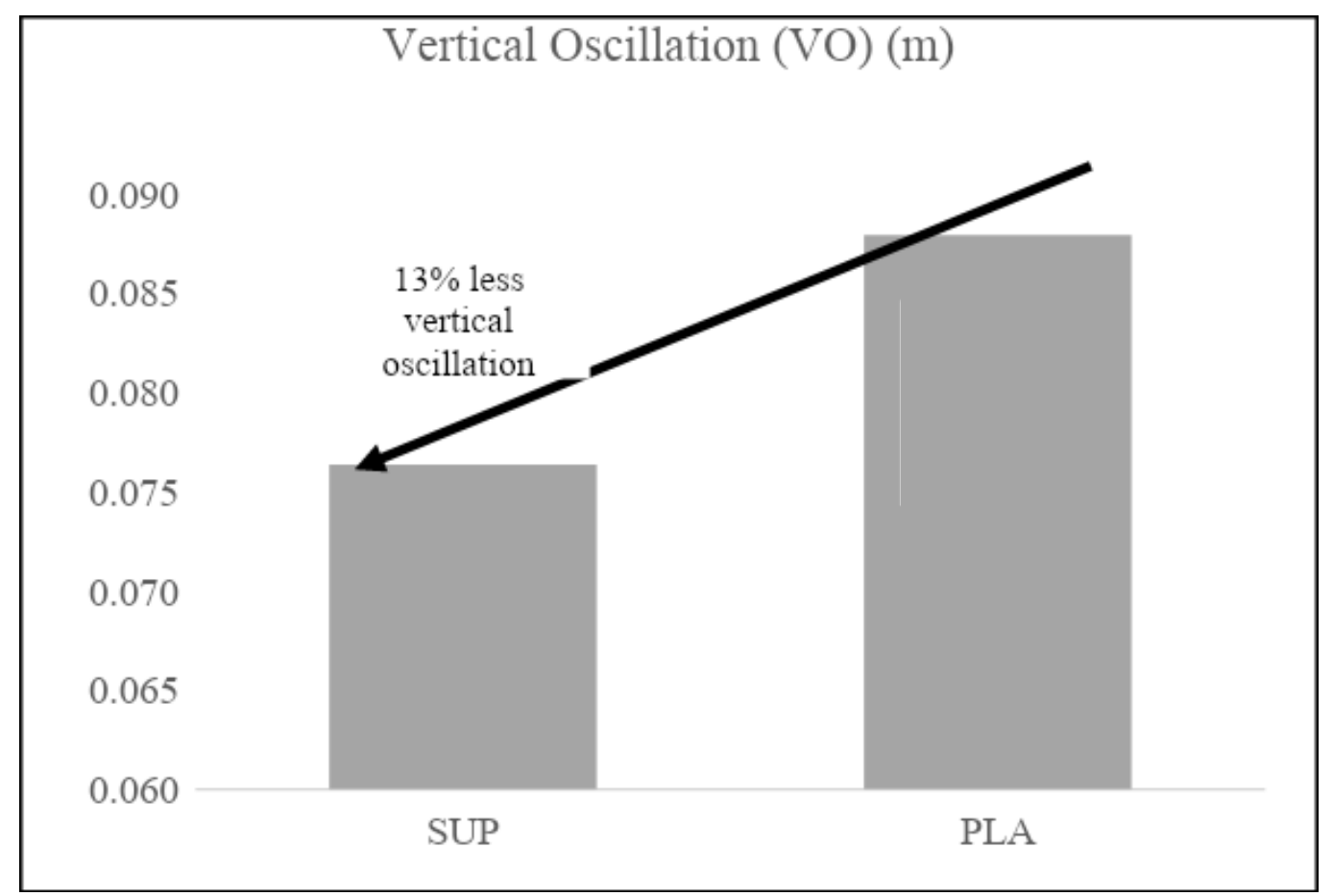


Discussion

Many studies suggest that BCAAs do not directly enhance performance, however most do not look at exercise training quality and the effect that this may have long term beyond the 10-12 weeks of observation seen in most studies (29). If exercise sessions can be performed with increased quality, it can be assumed that over time, an athlete may experience an improved adaptive response to their training program and ultimately improve performance.

For a given aerobic activity like running, some individuals are more economical than others (30). Running economy is an important performance indicator as variability in economy among a homogenous group of distance runners accounts for $20-30 \%$ of the differences in performance of trained distance runners at a given submaximal running speed as measured by oxygen consumption ( $\mathrm{ml} / \mathrm{kg} / \mathrm{min})(31-34)$. Many factors influence these inter-individual differences in running economy such as training, environment, physiology, biomechanics, and anthropometry - with each category having many additional influencing factors (15). Our study looked at factors that directly influence running biomechanics such ground contact time, flight time, and vertical oscillation.

In agreement with (30), GRF characteristics such as GCT and FT did not exhibit a statistically significant difference in running economy, and in our study we observed no difference in these characteristics between SUP or PLA. Our study did show a statistically significant difference in VO when the runner was on SUP vs a PLA, possibly indicating greater coactivation between two-joint muscles of the leg during stance (35). Greater co-activation among two-joint muscles of the leg during stance allows the neuromuscular system to transfer joint rotations more efficiently into desired external forces (36). In addition, greater co-activation between two-joint muscles of the leg provides greater stability to the runner during ground 
contact, reducing potentially wasteful vertical motion (VO), as reflected by vertical impulse measurements (30). While we did not directly measure force characteristics such as vertical impulse, we did measure vertical displacement of the center of mass through video analysis and found that when on SUP, the athlete had significantly reduced vertical displacement by $13 \%$ with a corresponding $8 \%$ decrease in flight time, possibly suggesting a greater co-activation between two-joint muscles of the leg and better stability during stance (36).

While many studies demonstrate improved muscle recovery characteristics with BCAA supplementation, the author of this study did not uncover any research that looked directly at whether or not improved recovery altered running mechanics as a result of improved force-time characteristics. (37) and (30) showed that more economical runners exhibited less vertical oscillation and that this can contribute to a significant amount of variability (36\%) in running economy. Because our runner exhibited less VO while on the BCAA supplement, we theorize that greater muscle recovery underpinned by changes in MPS, might contribute to an improved running economy, or a reduction in aerobic demand for a given task (11). Nutrition to support optimal muscle recovery to sustain high work outputs during repeated exercise bouts may ultimately enhance training adaptations and performance as indicated by force generating capabilities (11, 30, and 35). Since direct force measurements were not utilized in this study, further research may want to repeat this experiment with force measuring devices in a similar capture zone.

\section{Conclusions}

Our study suggests that BCAA supplementation surrounding key training sessions may help improve force-time characteristics of running mechanics during running. This may be attributed to improved muscle recovery and a reduction in associated fatigue symptoms caused 
by regular training, which in turn may increase preparedness to train. Our athlete consumed approximately $10 \mathrm{~g}$ of amino acids per day surrounding exercise sessions and this amount has been confirmed in the research as an effective dosage to stimulate and increase MPS postexercise $(4,19,38)$. Based on these findings, we recommend BCAA supplementation for athletes who are undergoing chronic endurance training.

Abbreviations

BCAA $=$ branched-chain amino acid

SUP $=$ supplemental BCAA condition

PLA = placebo condition

MPS $=$ muscle protein synthesis

$\mathrm{GRF}=$ ground reaction forces

$\mathrm{GCT}=$ ground contact time

$\mathrm{FT}=$ flight time

$\mathrm{VO}=$ vertical oscillation

Declarations

Ethics approval and consent to participate

This study was approved by the East Tennessee State University's Institutional Review

Board. Participant read and signed an informed consent document as approved by the Institutional Review Board.

Consent for publication

Not applicable.

Availability of data and material 
The data sets and analysis are available upon request to the corresponding author.

Competing interests

The authors declare that there are no competing interests with this manuscript.

Funding

The nutrition supplements used in this study were provided by Amino Vital.

Authors' contributions

K.S. conceived the idea for this study and obtained nutritional supplements from Amino Vital as the project lead. T.W. carried out this research project and wrote the manuscript as part of her dissertation work. C.B. and B.H.D. served as T.W.'s dissertation committee members and editors to this manuscript. M.H.S. served as chair to T.W.'s dissertation committee in approving and editing this research on behalf of the Sport, Exercise, Recreation, and Kinesiology department at East Tennessee State University.

Acknowledgements

The author of this manuscript would like to thank the department of Sport, Exercise, Recreation, and Kinesiology at East Tennessee State University for their continued education and support. She would also like to thank Amino Vital for allowing us to carry out this research project.

Authors' information

Tara Whiton is a professor of Community Health at the University of Maine at Presque Isle. She recently completed her $\mathrm{PhD}$ at East Tennessee State University in the Sport Physiology and Performance program where she conducted research for a NSF certified sport supplement. 
References

1. Peake J, Nosaka K, Suzuki K. Characterization of inflammatory responses to eccentric exercise in humans. Exerc Immunol Rev. 2005;11:64-85.

2. Hyldahl RD, Hubal MJ. Lengthening our perspective: morphological, cellular, and molecular responses to eccentric exercise. Muscle Nerve. 2014 Feb;49(2):155-70.

3. Hayashi K, Katanosaka K, Abe M, Yamanaka A, Nosaka K, Mizumura K, et al. Muscular mechanical hyperalgesia after lengthening contractions in rats depends on stretch velocity and range of motion. Eur J Pain Lond Engl. 2017;21(1):125-39.

4. Beelen M, Burke LM, Gibala MJ, van Loon L JC. Nutritional strategies to promote postexercise recovery. Int J Sport Nutr Exerc Metab. 2010 Dec;20(6):515-32.

5. Blomstrand E, Ek S, Newsholme EA. Influence of ingesting a solution of branched-chain amino acids on plasma and muscle concentrations of amino acids during prolonged submaximal exercise. Nutr Burbank Los Angel Cty Calif. 1996 Aug;12(7-8):485-90.

6. Kim D-H, Kim S-H, Jeong W-S, Lee H-Y. Effect of BCAA intake during endurance exercises on fatigue substances, muscle damage substances, and energy metabolism substances. J Exerc Nutr Biochem. 2013 Dec;17(4):169-80.

7. Matsumoto K, Koba T, Hamada K, Sakurai M, Higuchi T, Miyata H. Branched-chain amino acid supplementation attenuates muscle soreness, muscle damage and inflammation during an intensive training program. J Sports Med Phys Fitness. 2009 Dec;49(4):424-31.

8. Sharp CPM, Pearson DR. Amino acid supplements and recovery from high-intensity resistance training. J Strength Cond Res. 2010 Apr;24(4):1125-30.

9. Fouré A, Bendahan D. Is Branched-Chain Amino Acids Supplementation an Efficient Nutritional Strategy to Alleviate Skeletal Muscle Damage? A Systematic Review. Nutrients. 2017 Sep 21;9(10).

10. Burd NA, Tang JE, Moore DR, Phillips SM. Exercise training and protein metabolism: influences of contraction, protein intake, and sex-based differences. J Appl Physiol Bethesda Md 1985. 2009 May;106(5):1692-701.

11. Moore DR, Camera DM, Areta JL, Hawley JA. Beyond muscle hypertrophy: why dietary protein is important for endurance athletes. Appl Physiol Nutr Metab Physiol Appl Nutr Metab. 2014 Sep;39(9):987-97.

12. Appell HJ, Soares JM, Duarte JA. Exercise, muscle damage and fatigue. Sports Med Auck1 NZ. 1992 Feb;13(2):108-15.

13. Fridén J, Lieber RL. Structural and mechanical basis of exercise-induced muscle injury. Med Sci Sports Exerc. 1992 May;24(5):521-30. 
14. Kuipers H. Exercise-induced muscle damage. Int J Sports Med. 1994 Apr;15(3):132-5.

15. Saunders PU, Pyne DB, Telford RD, Hawley JA. Factors affecting running economy in trained distance runners. Sports Med Auckl NZ. 2004;34(7):465-85.

16. Koopman R, Beelen M, Stellingwerff T, Pennings B, Saris WHM, Kies AK, et al. Coingestion of carbohydrate with protein does not further augment postexercise muscle protein synthesis. Am J Physiol Endocrinol Metab. 2007 Sep;293(3):E833-842.

17. Staples AW, Burd NA, West DWD, Currie KD, Atherton PJ, Moore DR, et al. Carbohydrate does not augment exercise-induced protein accretion versus protein alone. Med Sci Sports Exerc. 2011 Jul;43(7):1154-61.

18. Tipton KD, Ferrando AA, Phillips SM, Doyle D, Wolfe RR. Postexercise net protein synthesis in human muscle from orally administered amino acids. Am J PhysiolEndocrinol Metab. 1999 Apr 1;276(4):E628-34.

19. Levenhagen DK, Gresham JD, Carlson MG, Maron DJ, Borel MJ, Flakoll PJ. Postexercise nutrient intake timing in humans is critical to recovery of leg glucose and protein homeostasis. Am J Physiol Endocrinol Metab. 2001 Jun;280(6):E982-993.

20. Tarnopolsky M. Protein requirements for endurance athletes. Nutr Burbank Los Angel Cty Calif. 2004 Aug;20(7-8):662-8.

21. Howarth KR, Phillips SM, MacDonald MJ, Richards D, Moreau NA, Gibala MJ. Effect of glycogen availability on human skeletal muscle protein turnover during exercise and recovery. J Appl Physiol Bethesda Md 1985. 2010 Aug;109(2):431-8.

22. Newsholme EA, Blomstrand E. Tryptophan, 5-Hydroxytryptamine and a Possible Explanation for Central Fatigue. In: Fatigue [Internet]. Springer, Boston, MA; 1995 [cited 2018 May 28]. p. 315-20. (Advances in Experimental Medicine and Biology). Available from: https://link.springer.com/chapter/10.1007/978-1-4899-1016-5_25

23. Lemon PW, Mullin JP. Effect of initial muscle glycogen levels on protein catabolism during exercise. J Appl Physiol. 1980 Apr;48(4):624-9.

24. Bowtell JL, Leese GP, Smith K, Watt PW, Nevill A, Rooyackers O, et al. Effect of oral glucose on leucine turnover in human subjects at rest and during exercise at two levels of dietary protein. J Physiol. 2000;525(1):271-81.

25. MacLean DA, Graham TE, Saltin B. Branched-chain amino acids augment ammonia metabolism while attenuating protein breakdown during exercise. Am J Physiol. 1994 Dec;267(6 Pt 1):E1010-1022.

26. Berthon P, Fellmann N. General review of maximal aerobic velocity measurement at laboratory. Proposition of a new simplified protocol for maximal aerobic velocity assessment. J Sports Med Phys Fitness. 2002 Sep;42(3):257-66. 
27. Noakes TD, Myburgh KH, Schall R. Peak treadmill running velocity during the VO2 max test predicts running performance. J Sports Sci. 1990;8(1):35-45.

28. Parker RI, Vannest KJ, Davis JL, Sauber SB. Combining Nonoverlap and Trend for SingleCase Research: Tau-U. Behav Ther. 2011 Jun;42(2):284-99.

29. Chromiak JA, Smedley B, Carpenter W, Brown R, Koh YS, Lamberth JG, et al. Effect of a 10 -week strength training program and recovery drink on body composition, muscular strength and endurance, and anaerobic power and capacity. Nutr Burbank Los Angel Cty Calif. 2004 May;20(5):420-7.

30. Heise GD, Martin PE. Are variations in running economy in humans associated with ground reaction force characteristics? Eur J Appl Physiol. 2001 May;84(5):438-42.

31. Conley DL, Krahenbuhl GS. Running economy and distance running performance of highly trained athletes. Med Sci Sports Exerc. 1980;12(5):357-60.

32. Daniels J, Daniels N. Running economy of elite male and elite female runners. Med Sci Sports Exerc. 1992;24(4):483-9.

33. Daniels JT. A physiologist's view of running economy. Med Sci Sports Exerc. 1985 Jun;17(3):332-8.

34. Morgan DW, Craib M. Physiological aspects of running economy. Med Sci Sports Exerc. 1992 Apr;24(4):456-61.

35. Heise GD, Morgan DW, Hough H, Craib M. Relationships between running economy and temporal EMG characteristics of bi-articular leg muscles. Int J Sports Med. 1996 Feb;17(2):128-33.

36. van Ingen Schenau GJ, Boots PJ, de Groot G, Snackers RJ, van Woensel WW. The constrained control of force and position in multi-joint movements. Neuroscience. 1992;46(1):197-207.

37. Williams KR, Cavanagh PR. Relationship between distance running mechanics, running economy, and performance. J Appl Physiol Bethesda Md 1985. 1987 Sep;63(3):1236-45.

38. Pasiakos SM, McClung HL, McClung JP, Margolis LM, Andersen NE, Cloutier GJ, et al. Leucine-enriched essential amino acid supplementation during moderate steady state exercise enhances postexercise muscle protein synthesis-. Am J Clin Nutr. 2011 Sep 1;94(3):809-18. 


\section{Figures}

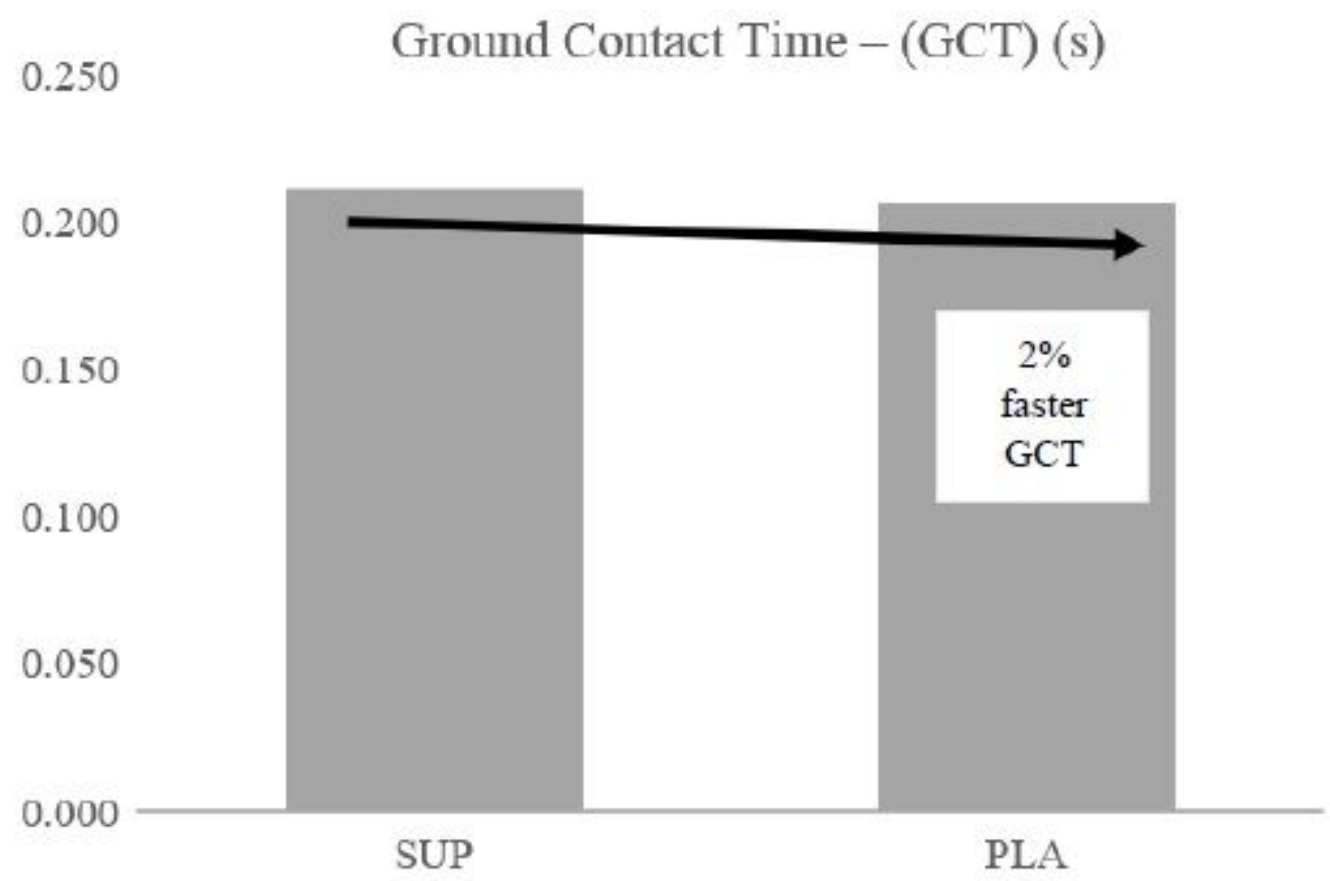

Figure 1

Ground contact time for SUP and PLA conditions

Flight Time - (FT) (s)

0.040

0.035

0.030

0.025

0.020

0.015

0.010

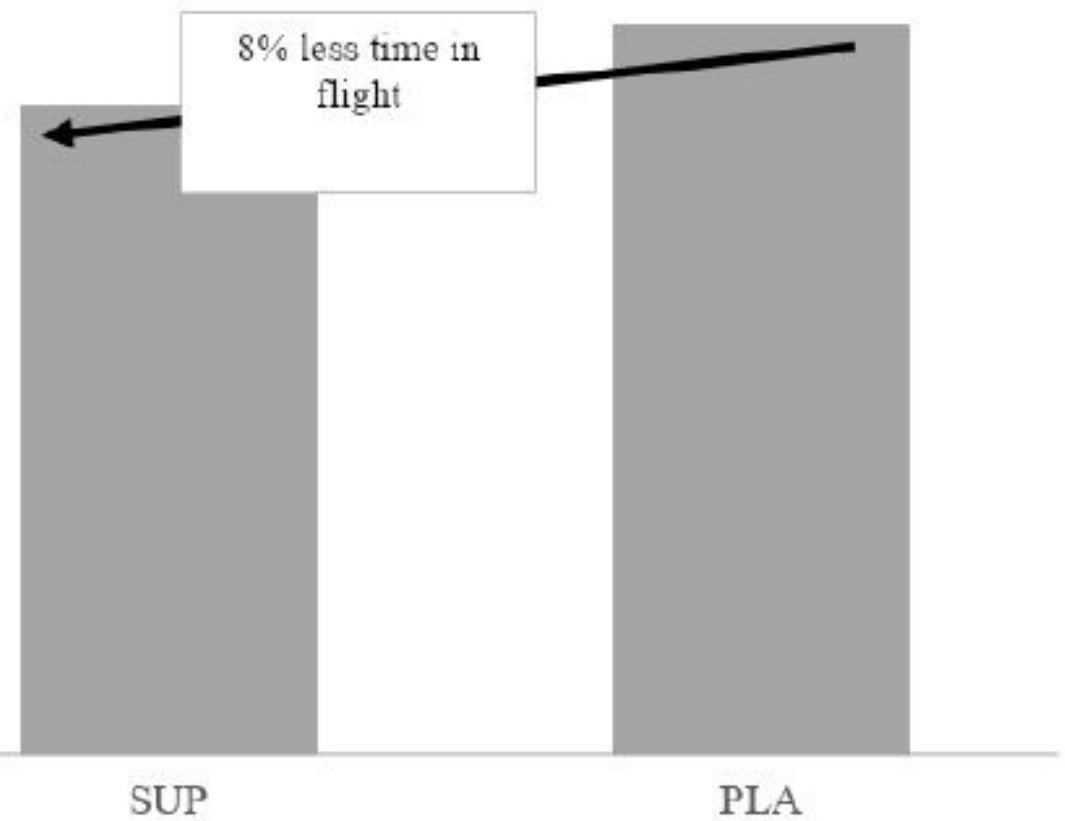

Figure 2

Flight time on SUP vs PLA conditions 


\section{Vertical Oscillation (VO) (m)}

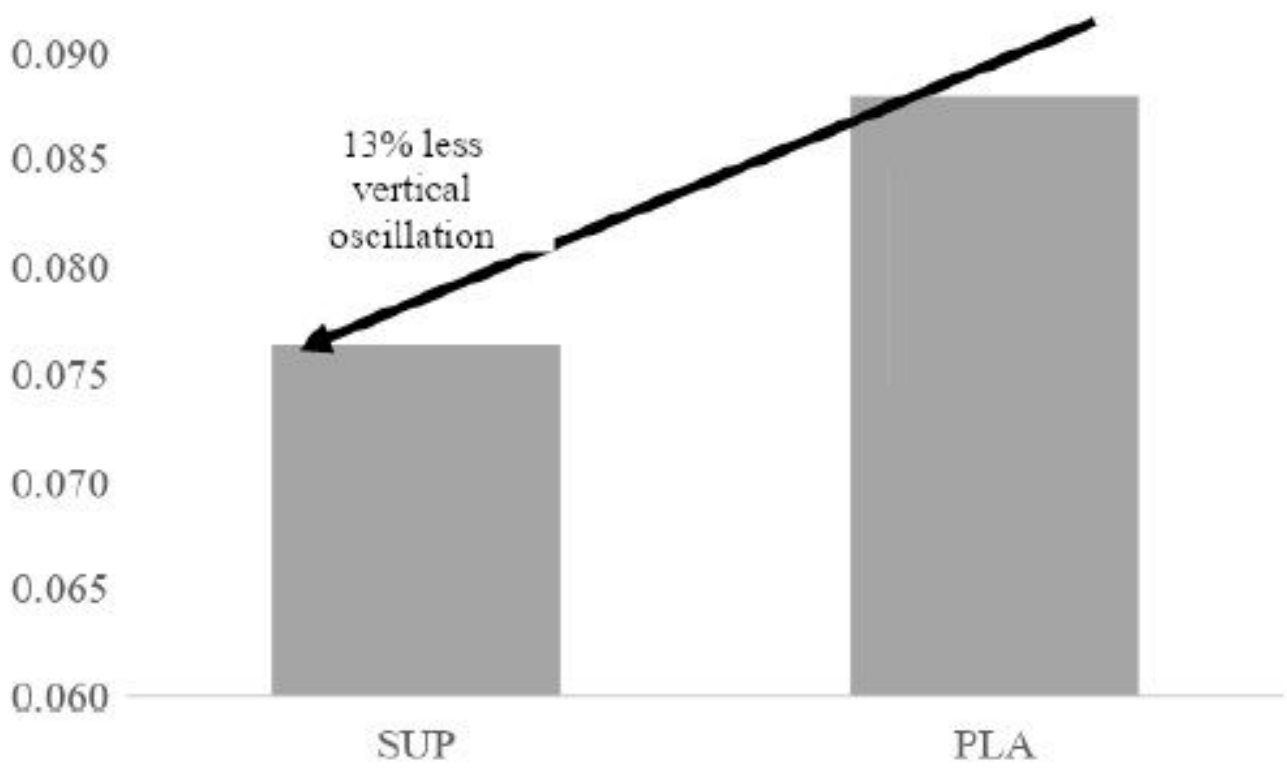

Figure 3

Vertical oscillation on SUP vs PLA conditions 